\title{
The Content Analysis of the English Text-General Certificate English
}

\author{
Saeed Ahmed \\ Research Scholar, Hamdard Institute of Education and Social Sciences, Hamdard University Karachi, Pakistan
}

\begin{abstract}
The O level schools in Pakistan prepare students for General Certificate English of Cambridge. These schools are popular to create competent, resourceful and creative students in entirely different cultures of the world. The O level qualified students are comparatively successful in getting elevated positions in service and turnout to be more resourceful professionals in their future enterprise. The prominence of $O$ level education is by virtue of its well-defined content-based books and updated assessment and evaluation system. In view of the pivotal role played by $O$ level textbooks the researcher is interested to analyze General Certificate English (Textbook) as a main corpus, and will assess its overall worth for second language learners. The main content areas of the text under focus are: cultural input, range of study skills contents, vocabulary criteria and the themes and topics. The research attempts to analyze how given contents introduced into the book help out nonnatives to develop their language for academic and professional needs in Pakistani context and provides suitable recommendations.
\end{abstract}

Index Terms: Content Analysis, Language Skills, Language Structures, O'Level Education

\section{Introduction}

'General Certificate English' is taught at O' Level schools in Pakistan and many other South and South East Asian countries. The book is written by Alan Etherton. The edition is published in 2001 by Thomas Nelson \& Sons Ltd-The United Kingdom and printed by Multivista Global Ltd. The main aim of the book is to help students who are preparing for the GCE (Overseas) English Language Examination (Etherton, 2001). The author wrote that:!

"In addition to a problem in the use of English, many students lack a sound understanding of the techniques required in writing acceptable compositions, in answering comprehension questions and in making a summary. Even when they have the intellect and command of language needed for this level, they lose marks unnecessarily by laying out their answers incorrectly and by being unaware of the standard expected by the examiners" (p. v). Finally, he concluded as "A major purpose throughout this book, therefore, is to give students enough guidance to enable them to reach the highest standard they are capable of, without being handicapped by ignorance of what they are expected to do or of how to do it" (p.v).

\section{The present research aims at making a thorough content analysis of:}

a. Cultural element in line with criteria given by Byram (1993)

b. Diversity and suitability of themes to instill motivation for learning

c. Vocabulary: the way it focuses on problems of usage related to social background, relevance to background of the learners and selects vocabulary assuming frequency, and the way it has been presented

d. The range of study skills to make learning and teaching productive.

According to Berelson (1952), content analysis is a systematic, replicable technique to minimize the large number of textual words into fewer content categories based on clear-cut rules of coding. All the contents will be classified into different categories and sub-categories for more explicit analysis on the text. The work, a researcher expects, will broaden a pedagogical insight for those who are involved in teaching and learning process. It will also be supportive for those interested in making content analysis related research. The researcher believes that the critical analysis of these contents for the book would mean broader and more valid conclusions of the book.

\section{Theoretical Framework}

Samovar et al. (2000:36) define culture as "the deposit of knowledge, experience, beliefs, values, actions, attitudes, meanings, hierarchies, religion, notions of time, roles, spatial relations, concepts about the universe, and artifacts acquired by a group of people during the course of generations through individual and group striving." Thus, learners, in a course of learning target language must strive to understand the beliefs, attitudes, concepts, actions and living styles of both their own and the foreign culture. And, all "textbooks introduce students the cultures of different countries and regions, thus making it convenient for students to exert 
a relatively remarkable influence on the fostering of students' cultural awareness and competence of intercultural communication" (Juan 2010, p.1). And "Systematic and comprehensive textbook may facilitate the culture input considerably, while a rigid textbook may leave no room for culture teaching, so the evaluations of textbooks are essential in FLE" (Ibid).

General Certificate English facilitates completion of a language tasks through some cultural input for the learners, but the question is as to what features of culture and how it has been showcased in the text. And is it advantageous or disadvantageous for the learners? In support of research, the researcher deems it necessary to evaluate this aspect of textual content with various angles and dimensions.

The inclusion of local culture in teaching has an exceptionally positive impact upon the minds of learners. It accentuates more receptivity to the target language. This view is also supported by Cunnings worth (2002, p.7) that the "teaching materials can exert considerable influence over what teachers teach and how they do it" Prodromou (1988) and Alptekin (1993) are of the opinion that the foreign culture may develop some confusion for the readers as they are not fully aware of that. Culture differs from society to another; hence it generates a difference in curriculum and the teaching methodology. Culture promotes understanding if it is rightly embedded with language. In an attempt to gauge the level of students' motivation, the detailed analysis on this aspect will be made and discussed in findings.

The themes and topics are very significant in any textbook as they are harbingers of maintaining learner's interest and enthusiasm if they are rightly organized and placed into a text. In addition to that, if learners find the themes interesting and according to their knowledge then the learning and teaching becomes more productive. Finally, wide range of diversity in themes provides an opportunity to the learner to discuss and interact with each other with same interest, break their boredom and promote spontaneous learning. Wachs (1994), while discussing the significance of a theme-based learning states that what is meant by the theme is a topic or subject ripe with potential for discussion, which English activities can revolve around and exploit for its language potential. A good topic may provide an opportunity where learners can negotiate with each other, build understanding, become receptive to learning and eventually an academic collaboration crop up.

Another necessary element in the text relates to the analysis of range of Study Skills. According to Mary and Waters (1992, pp.263-264) "What skills do students need in order to study effectively; the answers are likely to include the items in most typical study skill materials, for example, note-taking, skimming and scanning, using the library etc..". He elaborates that "such skills may not be sufficient for successful study, but their internalization, by one method or another, is surely a necessary part of successful study."

Traditional study skills are mostly significant to make learner's learning process and teacher's pedagogy to be more productive, less time-consuming and easy classroom. Furthermore, study skills approach allows learners to maximize their potentials for effective learning and help to minimize their learning anxiety.

In view of the aforementioned factors, the study of study skills used throughout the text becomes significant. It will be analyzed as to what extent the text caters for these approaches such as, skimming, scanning, reviewing, note-taking and summarizing. Lastly, how and when they are introduced through the larger textual passages at pre-study and post-study levels throughout GCE.

The main parts of the textbook relate to summary, reading comprehension, writing and communication, vocabulary building, and oral English. The researcher considers that the students' sufficient knowledge of study skills may enable them to cope with the text. The author of the book is also very particular that the students' basic linguistic competence may be built up so that they can do better in exams and avoid unnecessary loss of marks. The author admitted that $(2004$, p.1), the superficial understanding of these basic communication skills leaves the students handicapped in exams, and they are not able to get good marks. According to the author, "students lack certain methods in summarizing and note-taking and examiners are looking for something more than the superficial understanding of the facts".

The last content area to be analyzed refers to vocabulary input into the textbook. According to Ediger (1999), "variety in selecting words to convey accurate meanings is necessary in speaking and writing, the outgoes of the language arts." While Alexander (n.d) call vocabulary to be important because it increases comprehension, improves all skills of language (listening, speaking, reading and writing) and gradually boosts academic and social confidence.

The students at $\mathrm{O}$ level stage mostly tend to have the insufficient vocabulary to fulfill their exam needs. Therefore, the author has listed complete separate chapter on vocabulary in the text for the students.

To conclude, a productive teaching and learning take place when the text in question is relevant to stipulate study skills. Students' interest for learning develops when they explore themes and topics likely to their knowledge and culture. Students competence in any language program can be better measured by the range of vocabulary they store, retrieve and apply in their communications. The writer of this article will analyze and evaluate the vocabulary content of GCE in line with criteria propounded by Al-momani (1998). 
In order to analyze these factors in GCE, various statistical figures, such as frequencies, percentages, etc. will be slot in order to present data obtained from the text. The entire data to be presented through tables and charts for reliability purposes.

\section{Research Question}

This study sought to respond to the following research-based questions. What cultural content is available in GCE? What are its features? What are its advantages and disadvantages? How far the social and cultural contexts are found appropriate in the book in light of Byrams (1993) criteria? How do the exercises and activities encourage the students' active participation? To what extent do the exercises and activities meet the background and interests among the students? To what extent do the exercises and activities provide for the development of study skills, such as skimming, note taking, outlining, summarizing and looking up words into the dictionary? To what extent does the vocabulary of GCE is consistent in the vocabulary analysis criteria of Al- Momani (1998)? In general, what category does the book need to improve on?

\section{Method}

For this study, the researcher was interested to choose content analysis as the viable method. The goal was to provide a more systematic and accurate information for stronger inferences. As Weber (1990) indicates that "Content analysis is a research method that uses a set of procedures to make valid inferences from the text" (p. 9). Holsti (1969), put it as, "any technique for making inferences by objectively and systematically objectifying specified characteristics of messages."

The major instrument will be the checklist for the analysis of the specified contents. According to Soori, Kafipour and Souri, (2011, p.481), "textbook developers, by using appropriate checklists, can include more universal features in their EFL/ESL textbooks which, at the same time, are tailored and adapted to the needs of the learners. Examining all aspects of EFL/ESL textbooks and comparing them against an assessment tool such as an evaluation checklist ensures that significant factors will not be missed". There are diverse views upon the preparation of check lists. Ansary and Babaii (2002) argue that no neat formula can be availed to assess the overall worth of any textbook. They therefore compiled a list of what they deem to be a set of theoryneutral and universal features of EFL/ESL textbooks. Sheldon's (1988) produced one of the most extensive checklists that attempts to assess all aspects of content including such diverse factors as graphics and physical characteristics to authenticity and flexibility. The present study included checklists representing language structures and cognitive processes involved in understanding and analyzing new concepts and concurrently meeting course objectives and learners' needs and processes.

Regarding qualitative and quantitative analysis, according to Holsti, "qualitative method of content analysis is insightful, whereas quantitative method of content analysis is mechanical. The relationship is a circular one; each provides new insights on which the other one can feed" $(1969$, p. 11). In this way, the writer in this study considers both methods practicable.

\section{A. Validity of the Instrument}

In terms of Validity and Reliability, McAlpine (2002, p.11) points out, “ it is crucial to make sure that the assessment is both valid-in that it tests relevant skill or ability, and that it is reliable-in that the same results would be achieved if you repeated the assessment." He classified validity further into content validity, construct validity and predictive validity.

The check lists will be designed in relation to contents present throughout of the book. The checklist will comprehensively cover all the pre-determined contents (themes, study skills, culture and vocabulary) in the book. Construct will be tangible, as it directly covers the content domains (cultural input, study skills, themes and vocabulary) in the book, therefore, the content validity will be higher. The researcher has added a few more categories to be classified and categorized to ensure comprehensive validity. Efforts have been made to codify all important areas of the corpus under analysis, and check their proportions and suitability in relation to learn ability and teach ability.

\section{B. Reliability}

A balanced assessment needs to be valid and reliable. Underhill (1987) suggests that reliable tests give consistent results and if learners are tested two or three occasions, they get the same score each time. In order to ensure reliability of content analysis the researcher establishes some general coding rules to ensure consistency throughout the text. Secondly, a preplanned set of themes and codes were structured. Thirdly, the entire text was coded to develop coding and the checklist around which researcher found to be supportive in making analysis doable. Fourthly, all concepts and codes will be counted, and their frequencies tallied and the whole procedure will be repeated to ensure that the reliability is greater. 


\section{Corpus of the Study}

The researcher will analyze cultural content for the book by using Byram's checklist. The other areas include the provision of study skills, textual themes and the vocabulary.

\section{i. Brief Analysis of Cultural Content in GCE \\ V. Results/ Findings}

A close look at the text reveals that it contains several themes with varied concepts and values, which represent certain cultural context. It is very obvious, that whoever the writer is, and whatever the target audience, the text still gratifies for greater opportunities to cultural input. Regarding the indigenous culture of the students who are studying in Pakistan, the analysis unearthed that the textbook in question has not acknowledged due attention by the writer to embrace indigenous themes, which represent local culture of the students. One of the possible reasons can be that the book is specifically written for O level students, and it is used in the classrooms of several South and South East Asian countries that represent huge diversity in their culture and civilization. Thus, the cultural elements that the textbook in question seems to have international connotation and tone rather than being focused upon narrow cultures of the readers.

Now the point in question is as to what aspects of cultural input generally reflect the texts. Byram (1993), points out the following eight aspects/criteria as central in analyzing various cultural dimensions in any textbook: social identity and social group, social interaction, belief and behavior, social and political institutions, socialization and life cycle, national history, national geography, and national identity of a particular environment. In support of Byram's view, the researcher focused his study on these main headings/ codes.

The analyses as in table-1 given below indicate that the GCE devotes a lot of contents related to geographic items. About $44 \%$ percent of the text, especially part 1-2-3 incorporates names of geographical items at many passages such as names of islands, continents, banks, rivers, plateaus and various regions. The second heading social identity and social group constitute about 23.7 percent of the text which is about some British Royal names, institutes and some Europeans literary figures. The third category emanates from Social interaction, beliefs and behaviors, and social and political institutions and that constitute $19.2 \%, 7.8 \%$ and $5.3 \%$ of the text respectively. The introduction of some top-level institutes, i.e., University of Cambridge, and some top personalities like Queen Elizabeth may trigger some awareness in the minds of pupils regarding the target culture of the language. The text contains a lot of information about British political system, geography and some prominent British personalities that makes the pupils aware of British culture and its epigrammatic history.

The first two chapters of the text are allocated to teaching Summary Writing and Comprehension. Writer has introduced diverse themes in reading comprehension and summary. The topics such as "Story about racism in South Africa" (p.71, 72), Farewell to Civilization (p.87, 88), Sahara desert (p.12) etc. reflect foreign culture. These topics are highly alluring and may persuade learners to boost more curiosity to develop language further into depth through these universal topics. The topics such as, Journey into Amazon pp.43-44-Mrs. Brim low p.48 -A sharp detective p.52,53,54 -Criteria for good cultivation and yield pp.59-60-Pets and license p.65Malnutrition p.68-Pisces iii p.69- The war of the world's p.74-Unidentified Flying Object p.75,76-Titanic p.78Trees and benefits p.80, 81-Snow-starved Aps p.82-The Rift Valley p.83-Turtle and Tourists at loggerheads p.85-Wolves and Domestic dogs 86,87 are introduced in part- 2 of a book.

There are some interesting stories and scientific themes incorporated into the text which add to global awareness through language learning. The range of topics seems to be highly diversified, which will create demand for learning. This is one of the incredible ways the writer has used to encourage learners' enthusiasm for language learning by introducing contemporary society and commonplace themes from which students are generally aware. In this way, learners are provided an opportunity to discuss those topics together and exchange some cultural input from the outside world. The text as such, does not look like a hotchpotch of some boring linguistic exercises. Additionally, by introducing the topics of a contemporary world, the writer seems to have described international (Neutral) culture along with the target culture devoted to contemporary lives of some prominent figures and achievements of the target culture. Approximately, 55\% of the book takes in target language (British) culture, and about $45 \%$ contents relate to other cultures such as European and American.

These analyses established that language, and cultures are interrelated entities. According to Eli Hinkel, "text book is the effective instrument for the educational practice, and it can reflect values, and sense for individuals and nations" (2005, p.135). The flexible textbook, inculcates systematic and comprehensive cultural input, yields more positive results and the inflexible text never allows a room for cultural content. Kramsch (1993, p.218) also stressed the need to connect, 'the teaching of language to that culture'. The findings imply that GCE covers a vast amount of diverse themes, which reflect international and target culture. They are not only a source of information for the learner, but also generate enthusiasm for language learning. 


\section{ii. Study Skills in GCE}

Study skills refer to certain approaches or actions applied for successful learning."What skills do students need in order to study effectively', the answers are likely to include the items in most typical study skills materials, for example, note-taking, skimming and scanning, using the library, etc. Such skills may not be sufficient for successful study, but their internalization, by one method or another, is surely a necessary part of successful study (Mary and Waters, 1992, p.263-264)".

In the textbook, the greatest study skill, as the table-2 indicates via GCE, corresponds to look up word that covers $78.73 \%$ of the text. The text includes extensive reading passages and writing texts which require from students to refer to the meaning of word that they encounter. The application of enhancing word power ultimately involves more activities leading to dictionary use, pair discussion and other necessary tools. However, the least percentage pertains to summary practice albeit there is a separate chapter (1 and 2) on it. The study skill related to scanning and outlining is enormously projected with the percentage of $6.07 \%$ and 4.67 $\%$ respectively. The entire text covers a wide range of vocabulary-related skills, and strategies; whereas chapter 4 in the text is exclusively on vocabulary and types of vocabulary learning strategies.

The initial units within the GCE text are related exclusively with the task aimed at developing study competence of the students. A lot of practice and follow up exercises represent the text that involve application of traditional study skills. The initial three chapters from a book (summarizing p.2-29, comprehension, summary and directed writing p. 32-103) and communication in writing p.110-163) designate that the students are exposed to follow certain techniques such as note-taking, summarizing, skimming, and looking up for words that the writer thinks are essential parts of summarizing large textual passages. Since a hefty portion of the text is devoted to reading comprehension (see page 13-103), and summarizing (see page 2-29) the traditional study skills use is found to be paramount. What the learner requires at the initial level of their career is a deeper understanding of new concepts by use of some technical approaches in language learning. It is also a fact that, "such techniques cannot be mastered unless students are initially and continuously involved in learning to study at the deeper level....since the intended audience for the materials is a non-native speaker of English at intermediate level or above" ( Mary and Waters, 1992, p.267).

The controlled and guided way through which learners come across with different vocabulary items (see page 172-209) part 4 of the text makes the text, predominantly accessible for the learner. The writer has systematically and step by step introduced the vocabulary learning strategies. The main domains of study include phrasal verbs, idioms, common errors learners make, pairs of words, etc. There are variety of techniques suggested by the author regarding understanding of new words, making difference between two words having same spelling but different meaning, and the words that mostly confuse natives and non-native speakers.

The following illustrations reveal how and when the use of study skills has been demonstrated at different places throughout the text.

Unit 2, (p.3) of GCE elaborates some techniques to summary writing. According to the statement:

- Get a blue pencil and a red one (or an ordinary pencil and a pen). Use the red pencil to underline important points for the first part of a question. Then the text states "use the blue pencil to underline points for the second part of the question. This method prevents confusion and saves time.

- Read the question again very carefully.

- Use your rough notes to write your draft or (if you are good at this work) your final summary.

- Add or omit words to get to the right length ( see p.3)

In the above excerpts drawn from the text, we can see clear directions and explicit presentation of study techniques for the students to summary writing. We can clearly see (p.4-5-6) that the students engage into three consecutive exercises, which will allow teachers to assess how far they have mastered study skills such as reviewing, note-taking, summarizing, outlining and how strong their knowledge is.

Unit 22, (p. 61) articulate as 'Aids to better comprehension' the text showcased study skills for effective comprehension. For example, the author states, "in this unit we will consider quite simple ways in which you can improve your ability to understand a passage and to answer questions about it (see pp.61-64)". Later the writer describes 17 different study skill approaches to successful comprehension.

Unit 37 (pp.115-116) of GCE speaks about some note-taking methods. It guides students to use certain techniques to respond to a theme and write about it in an acceptable way. The unit is titled as "Compositionbasic points." The text describes, "in some cases, the theme is not clear, and there are many ways of writing about a topic. Then you can restrict the scope of your topic and use one of the methods shown by DAFTI. Study the following explanation. Then learn the five ways of DAFTI by heart.

$\mathrm{D}=$ Different types, attitudes, reasons or factors $\mathrm{A}=$ Advantages and disadvantages of a topic, $\mathrm{F}=$ Factual account $\mathrm{T}=$ Time or historical approach to a topic, I=Importance of a topic in the life of a man (See p.116). 
Unit 38 (p.119) titled 'Composition - making a plan'. There are some valid hints given to students to plan a composition piece. The text states, "there are three main steps in planning a composition." Unit 40 titled, 'Paragraphing and developing ideas' the text suggests, "there are two approaches to the use of paragraphs. We call them 'theory' and 'practice'. Unit 45 (p.136) titled 'Descriptive composition' the text suggests, “in a descriptive composition, you usually know what your theme is. You know which person, place or thing you have to describe. The two main problems are:

a) How can I make my description interesting?

b) How can I arrange my points in a sensible order?

The entire part-3 "Communication in writing: Composition" (see p.110-163) of the GCE pronounce balanced input of study skill approaches. This proves that the text exhibits outstanding manifestation of study skills for the learners who can benefit to obtain good results in the exam, consolidate their language base, and ultimately improve their personal and professional skills for good writing and reading. They can solve their exam issues with more confidence, can study faster, have the opportunity to save their time and avoid boredom.

\section{iii. Criteria of Vocabulary in GCE}

According to the findings Table-4 quantified below expound that the criterion 8 (level of appropriateness of new vocabulary) obtained the highest percentage followed by standard 5 (Coverage of vocabulary into suitable contexts or situations) with $60 \%$ and criterion 1(Relevance of the vocabulary to the students' background) with 55\%. The lowest percentage goes to criterion 4 (Phonetic Transcription of new vocabulary) with only $6 \%$. The researcher believes that the results are quite rational. For instance, concerning Criterion number 1, the topics given in part one of the textbook such as, Ants, lifestyle p.9-Sahara desert p.12Stamp collection p.15-Malaria p.17-Successful Ascents of Mountain Everest P.25-The Volcano p.29 are abundantly well known among the students, which offer better leverage to students to memorize words more capably.

Their encounter with new words would also be an enjoyable experience. For instance, students have much more heard and encountered about Malaria (p.17) in their everyday life. Ants are the common insects found everywhere in Pakistan and around the world. The vocabulary related to ant's lives, their living styles and adventures will for sure assist and call learners in imbibing more vocabulary. It will provide more control on their communication. Examples of this type of vocabulary are: ants, holes, colonies, inhabit, mosquitoes, malaria, survive, rugged mountains, peak, height, desert, sandy, tropica, etc.

As far as criteria number 3 and 7, the text does not furnish to elaborate unfamiliar words through a glossary. The difficult words are not listed, classified or phonetically transcribed where ever they show up in the text. Concerning part 6 (Oral English) of the text (see p. 308-313), the text seems to have given methods of transcription and their rules. However, this is the smallest presentation depicted at pre-study stage of new concept. For example, p.308 practice 1-A is about pronunciation practice, which states, "check that you can pronounce the letters 'qu' correctly in these words: Queen, Quiet, Question. Similarly, page 313 of the text comprises these headings: A. Pronunciation B. Reading aloud C. Picture discussion to clear learners' concepts for pronunciation.

Regarding criterion 5 (Coverage of vocabulary into suitable contexts or situations) the analysis revealed that it obtained the second highest frequency $(60 \%)$. There are plenty of practice exercises where learners are directed to decipher meaning of words through given context in all six parts of the book. Part 4 of the book titled "Vocabulary Development," is devoted to usage of vocabulary in different situation, and error correction of vocabulary. The main contents and sub-contents embrace prefixes, suffixes, idioms, phrases, and description of some common words with error correction. On these pages, we can see a lot more vocabulary of everyday use. There are quite a few exercises, which engage students to rectify their misconceptions about certain words, which are more often misunderstood and misused even by the expert users of English. Page 172 is titled as 'Words in Context' followed by the sub-title 'Guessing the Meaning'. The author writes, "don't worry about very difficult words within a passage. You may be able to guess their meaning."

A fussy look into the text yields these tasks and exercises (see p.172, 173, and 174) which gives clearer idea of the presentation of vocabulary:

Exercise-1 Briefly explain the meaning of each word in bold type below.

Exercise-2. Each of these sentences is ambiguous. Discuss what each sentence could mean. Pay attention to the words in bold type.

Exercise-3 Choose five of the words below. In each case, write two sentences to illustrate the different meanings which the word or expression can enclose.

Certain words seemed to re-surface into a textbook every now and then (item 2). Major chunk of such a category belongs to Academic Words, where activities and exercises involve tasks, questions, guidelines, 
directions and notes at pre-study stage. Such common words/phrases are: extracting information p.14, following passage p.17, describing p. 25, carry equal marks p.27, suitable p.33, above, below p.37, own p.36, explain p.87, briefly p.87, quote p.87, theme p.118, form p.156. Thus a frequent encounter with same words may ultimately allow better vocabulary comprehension, understanding of syntactic behavior and association of those words to the students.

According to Richards (1976), knowing a word means knowing how often it occurs, the company it keeps, its appropriateness in different situations, its syntactic behavior, its underlying form and derivations, its word associations, and its semantic features. It is very unlikely as a result, that an L2 student will be able to grasp meaning of a word in one encounter, unless he has the frequent encounter with them. Additionally, as the student meets the word through a variety of activities and in different contexts, a more accurate understanding of its meaning and use will develop. Various studies create a range of 5-16 encounters with a word in order for a student to truly acquire it (Nation, 1990: 43-5).

According to lexico-semantic theory, humans acquire words first and then, as the number of words increases, the mind is forced to set up systems which keep the words well-organized for retrieval (Lado, 1990). The human lexicon is, therefore, conceived to be a network of associations, a web-like structure of interconnected links (Aitchison, 1987). This re-iterates the fact that the teacher must help students to create those links and frame those associations for smooth vocabulary input. Therefore, an important aspect of this gradual learning is that the instructor consciously cues reactivation of the vocabulary. General Certificate English (GCE) caters for about $54 \%$ of item two (Recycling of vocabulary at different contexts). The graphic below illustrate the different types of English vocabulary and the situations in which they are likely to be found:

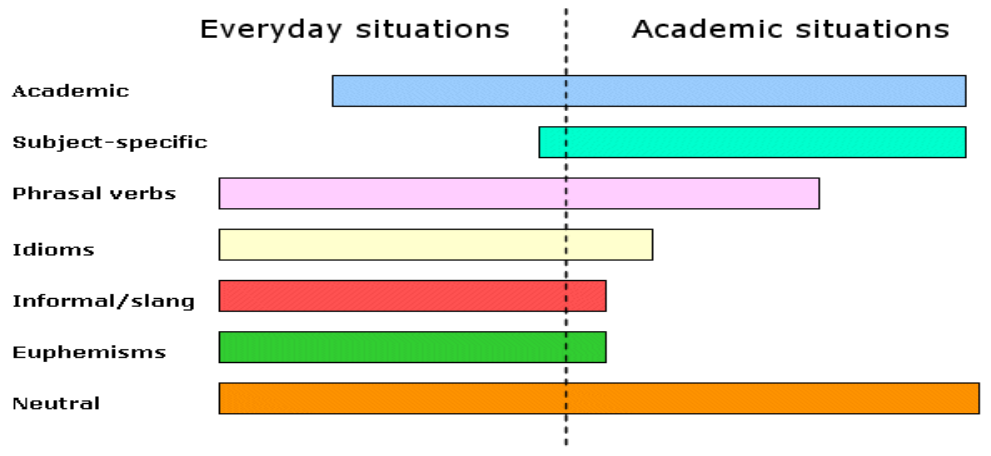

(Adopted from http://esl.fis.edu/learners/advice/vocab types.htm)

GCE is basically recorded to strengthen Language-Base and General English of students. Secondly, it aims at making better professionals. In GCE, the topics and themes are introduced from English Literature, Newspapers, and General Science into early chapters of a book. The percentage of Neutral Words (e.g., small, large, in my view, late, etc.) in the text stands largest ( $44.6 \%$ ), while the second greatest category is of Pairs of words (e.g., practice, practice, ) that is about (24\%). Subject Specific vocabulary (earth quacks, acacia tortilis seeds, malaria, etc, ) has the least percentage $(1.3 \%)$ in the table. The reason for this can be that the text is primarily written for developing General proficiency level of students rather than to promote their English for Specific Purposes.

The third largest frequency in the text is of Academic words (e.g., following, hence, given, before, after, above, explain, describe, carefully, etc.). The checklist indicates that these eight categories of words are both used in familiar situations and the academic situations. However, category number 4, 7, and 8 has overwhelming application in day to day use, which will serve learner's personal needs outside the class.

\section{Relevance of Vocabulary to learners' Background}

In terms of vocabulary presentation, the topics introduced in the text throughout six parts, exhibit a greater likely hood for learners to gain interest. The topics are of general interest to all learners and relevant to their background knowledge, which makes the text vocabulary easily comprehensible to the students (see table 4). This will also help in memorization of vocabulary for exam purposes. The topics such as: Accidents at home, describe accident, 140-at home 116,135,140-at school 162-traffic 117, 141-Animals behaving like an animal 132-Applying for a job 158-Banks 127-Brother, describe 116-Bureaucracy 132-Capital punishment 137Charity 132-Cooking, pleasures of 113-Cycling 133 which inculcate a vast amount of vocabulary that relates to the students' everyday life experiences. Topics like brother, banks, charity and traffic have much greater relevance to students' life. This confirms that the book provides a balanced approach in presenting vocabulary to students' background. However, the text has no glossary that lists words alphabetically in which the reader or 
learner can detect and find firstly, to the phonetic transcription of the word, and secondly, the meaning in English. This is one of the key shortcomings in the text.

\section{Conclusions}

The study demonstrated that the text was reasonably good and more specifically the positive side outweighed the negative features. It is believed that the:

- Textbook provides better representation of target and international culture. The range of topics is diversified and generates interest for learner.

- Textbook presents vocabulary in appropriate contexts and situations. Most of the vocabulary is potentially useful in everyday life situations. However, the textbook has no glossary at the end of every unit.

- Textbook, to a great extent provides very balanced use \& appropriate study range skills which makes learning \& teaching productive. Students as a result, will be able to get good marks in their exams.

\section{Suggestions For Further Studies}

1. It is possible to carry out additional research into the content analysis of GCE as it may uncover more useful results.

2. Same pattern of research for other English texts taught at Matriculation and Intermediate levels in Pakistan may be carried out to evaluate their overall worth for second language acquisition. This will provide better comparative analysis of $\mathrm{O}$ level text and the other texts taught at the Board of Intermediate and Secondary Education in Pakistan.

Despite the strengths and the weaknesses in GCE, it reveals that any superfluous concern might be eradicated by supplementing, modifying and adapting weaker aspects of the text. With both strong and the weak points, the text can still be the very effective tool for language acquisition provided that the teachers and the audience have a certain amount of abilities to exploit their benefits.

\section{References}

[1]. Al. Momani, Naeem. (1998) . Evaluation of EFL textbooks (AMRA) for the First and Second Secondary Classes in Jordan from Students, Teachers and Supervisors' Perspectives. Unpublished M. Ed. Thesis. Yarmouk University.

[2]. Alexander, F. (n.d.). Understanding Vocabulary. Retrieved August, 2013 from

http://www.scholastic.com/teachers/article/understanding-vocabulary

[3]. Ansary, H. \& Babaii, E. (2002). Universal characteristics of EFL/ESL textbooks: A step towards systematic textbook evaluation. The Internet TESL Journal, 8(2), available online at: http:/iteslj.org/Ansary-textbooks/

[4]. Byram, M. (1993). Language and Culture Learning: The Need for Integration. In Byram. M. (Ed)

[5]. Ediger, M. (1999). "Reading and Vocabulary Development." "Journal of Instructional Psychology", 26(1), 7-15.

[6]. Hinkel, Eli. (Ed.), (2005). Culture in Second Language Teaching and Learning. Shanghai: Shanghai foreign Language Education Press.

[7]. Holsti, O.R (1969). Content Analysis of Social Sciences and Humanities. Reading M.A Addison-Wesley. Asian EFL Journal, 9(2), 1-15. Retrieved on 2-9-2013, http/www.asian-efl-journal.com/7 June

[8]. Hutchinson, T \& Torres, D. (1994). The textbook as agent of change ELT Journal, 48, 315-328.

[9]. ISP Nation (1990). Teaching and Learning Vocabulary Heinle and Heinle Publishers, 1990

[10]. Jack C. Richards (1976). The role of vocabulary Teaching TESOL Quaterly Vol. 10 No-1 March 1976

[11]. Jean Aitchison (1987). Words in the mind: An introduction to the mental lexicon Oxford University Press, 2003

[12]. Kramsch, C. (1993). Context and Culture in Language Teaching. London: Oxford University Press.

[13]. Mary W. and Waters A. (1992) Study Skills and Study Competence: getting the priorities right. ELT Journal Volume 46/3 July 1992 @ Oxford University Press 1992

[14]. McAlpine. A (2002) Principles of Assessment Retrieved from: www.caacentre.ac.uk/dldocs/Bluepaper1.pdf (Sep 5, 2013)

[15]. Prodromou, L. 1988. 'English as Cultural Action'. ELT Journal. Volume 42/2.

[16]. Putri, H. F. (2010). The Importance of Vocabulary in English Learning. Retrieved Sep. 11,2013, from http://universityofibnkhaldunbogor-indonesia.blogspot.com/2010/01/importance-of-vocabulary-in-english.html

[17]. Samovar, L. A., \& Porter, R. E., Stefani, L. A. (2000) "Communication between cultures" Beijing: Foreign Language Teaching and Research Press.

[18]. Sheldon, L. (1988). Evaluating ELT textbooks and materials. ELT Journal, 42 (4), 237-246.

[19]. Soori, A. Kafipour, R. Sourcy, M. (2011). EFL Textbook Evaluation and Graphic Representation. European Journal of Social Sciences ISSN 1450-2267 Vol.26 No.3 (2011), pp. 481-493

[20]. Stewart Wachs, (1994), Leaving the Room: An Introduction to Theme-Based Oral English. The Internet TESL Journal, Vol. II, No. 1, January 1996 http://iteslj.org/Techniques/Wachs-ThemeBased.html

[21]. Swan, M. 1985. 'A Critical Look at the Communicative Approach'. ELT Journal. Volume 39/2

[22]. Underhill, Nic (1987). Testing the Spoken Language, New York: Cambridge University Press

[23]. WU Juan (2010), Canadian Social Science Vol. 6, No. 5, 2010, pp. 137-144 


\section{Appendices}

\begin{tabular}{|c|c|c|c|c|}
\hline Cultural content & Details & Position & Numbers & Percentage \\
\hline $\begin{array}{l}\text { 1. SOCIAL IDENTITY AND SOCIAL } \\
\text { GROUP }\end{array}$ & $\begin{array}{l}\text { Chapter-1 } \\
\text { Peter, } \\
\text { Queen Victoria } \\
\text { Sir Arthur Conan Doyle } \\
\text { Pisces v } \\
\text { Canadian Royal Navy } \\
\text { Peter Ibraham } \\
\text { H.G Wells } \\
\text { R. Gardiner \& D. Van der Vat } \\
\text { Victorian Novel }\end{array}$ & $\begin{array}{l}\text { p. } 2 \\
\text { p.15 } \\
\text { p. } 45 \\
\text { p.74 } \\
\text { p77 } \\
\text { p.78 } \\
\text { p.78 } \\
\text { p.79 } \\
\text { p. } 125\end{array}$ & 10 & $22.7 \%$ \\
\hline 2 SOCIAL INTERACTION & $\begin{array}{l}\text { Ch.3 } \\
\text { Thanks giving } \\
\text { Yours sincerely } \\
\text { Dialogue } \\
\text { The Greeting 'Dear Mary } \\
\text { Smith', Dear Mr. Lee } \\
\text { Dear sir }\end{array}$ & $\begin{array}{l}\text { p. } 21 \\
\text { p. } 22 \\
\text { p. } 142, \\
\text { p. } 144 \\
\text { p. } 151, \\
152\end{array}$ & 8 & $18.2 \%$ \\
\hline 3.BELIEF $\quad$ AND BEHAVIOUR & $\begin{array}{l}\text { Christmas, } \\
\text { Baobab } \\
\text { Night Spirits } \\
\text { Witches }\end{array}$ & $\begin{array}{l}\text { p. } 44 \\
\text { p. } 84 \\
\text { p. } 84 \\
\text { p. } 93\end{array}$ & 4 & $6.8 \%$ \\
\hline $\begin{array}{l}4 \text { SOCIAL AND POLITICAL } \\
\text { INSTITUTIONS }\end{array}$ & $\begin{array}{l}\text { Asphalt Pitch } \\
\text { University of London } \\
\text { University of Cambridge }\end{array}$ & $\begin{array}{l}\text { p.95 } \\
\text { p. } 77 \\
\text { p. } 12\end{array}$ & 3 & $5.3 \%$ \\
\hline $\begin{array}{l}\text { 5SOCIALIZATION AND THE LIFE } \\
\text { PHRASE }\end{array}$ & $\begin{array}{l}\text { Huge Generation gap } \\
\text { 6th century bc } \\
\text { Worldwide life }\end{array}$ & $\begin{array}{l}\text { p. } 112 \\
\text { p. } 87\end{array}$ & 2 & 4.9 \\
\hline 7 NATIONAL GEOGRAPHY & $\begin{array}{l}\text {-Chapter I } \\
\text {-King's Road, Sahara } \\
\text {-Egypt } \\
\text {-Mesopotamia } \\
\text {-Argentina, Siberia, Chile, China, USA, Middle East } \\
\text { and -Latin America, } \\
\text {-Solomon Islands } \\
\text {-Rhine } \\
\text {-Rhone } \\
\text {-Danube } \\
\text {-The Rift Valley } \\
\text {-Mediterranean } \\
\text {-Easter Island }\end{array}$ & \begin{tabular}{l|l} 
p. 6 \\
p. 12 \\
p. 12 \\
p. 12 \\
- \\
- \\
\\
\\
p. 83 \\
\end{tabular} & 18 & $42.1 \%$ \\
\hline TOTAL & & & 25 & $100 \%$ \\
\hline
\end{tabular}

Table - 2: $\quad$ Presentation of Study Skills in GCE

\begin{tabular}{|l|c|c|}
\hline Study Skills & Frequency & Percentage \\
\hline Scanning (Reviewing the data fast) & 20 & 4.67 \\
\hline Skimming (Getting the main idea) & 18 & 4.20 \\
\hline Note- Taking ( Note down key points) & 22 & 3.27 \\
\hline Outlining (Highlighting the gist of every paragraph) & 26 & 6.07 \\
\hline Summarizing & 5 & 1.16 \\
\hline Looking Up Words/ Using a Dictionary & 337 & 78.73 \\
\hline Total & 428 & $100 \%$ \\
\hline
\end{tabular}

Table-3: Frequency, Percentage and types of words (This is approximate number taken from GCE)

\begin{tabular}{|c|c|c|c|c|}
\hline Type of Words & $\begin{array}{l}\text { Everyday } \\
\text { Situations }\end{array}$ & $\begin{array}{l}\text { Academic } \\
\text { Situations }\end{array}$ & Frequency & Percentage $\%$ \\
\hline 1. Neutral Words (e.g., small, large, in my view, late etc.) & $\checkmark$ & $\checkmark$ & 3000 & 44.6 \\
\hline $\begin{array}{l}\text { 2. Antonyms, synonyms and homonyms (e.g., clear, } \\
\text { unclear, explicit, see, sea etc.) }\end{array}$ & $\checkmark$ & $\checkmark$ & 300 & 3 \\
\hline 3. Pairs of words (e.g., practice, practice) & $\checkmark$ & $\checkmark$ & 1700 & 24 \\
\hline 4. Phrasal verbs (e.g., call off, call on etc.) & $\checkmark$ & & 296 & \\
\hline $\begin{array}{l}\text { 5. Subject Specific ( earth quacks, acacia tortilis seeds } \\
\text { etc,) }\end{array}$ & $\checkmark$ & $\checkmark$ & 55 & 1.5 \\
\hline $\begin{array}{l}\text { 6. Academic (e.g., following, hence, given, before, after, } \\
\text { above etc.) }\end{array}$ & $\checkmark$ & $\checkmark$ & 1200 & 18.1 \\
\hline $\begin{array}{l}\text { 7. Idioms and Common Expressions (e.g., to burn a } \\
\text { midnight oil, under cloud etc.) }\end{array}$ & $\checkmark$ & $\checkmark$ & 130 & 1.9 \\
\hline 8. Euphemisms ( loggerheads, monotonous, tropical) & $\checkmark$ & $\checkmark$ & 700 & 6.9 \\
\hline
\end{tabular}




\begin{tabular}{|l|l|l|l|l|}
\hline Total & $\checkmark$ & $\checkmark$ & & 100 \\
\hline
\end{tabular}

Table - 4: $\quad$ Vocabulary in the GCE according to the criteria of Al-Momani (1998)

\begin{tabular}{|c|c|c|c|c|c|c|c|c|}
\hline Criterion & Part-1 & Part-2 & Part-3 & Part-4 & Part-5 & Part-6 & Total & $\%$ \\
\hline $\begin{array}{l}\text { 1. Relevance of the vocabulary to } \\
\text { the students' background }\end{array}$ & 80 & 219 & 77 & 219 & 106 & 30 & 572 & 55 \\
\hline $\begin{array}{l}\text { 2. Recycling of vocabulary at } \\
\text { different contexts }\end{array}$ & 73 & 88 & 103 & 150 & 92 & 12 & 518 & 54 \\
\hline 3. Provision of Word list & 0 & 0 & 0 & 211 & 116 & 0 & 142 & 6.3 \\
\hline $\begin{array}{l}\text { 4. Phonetic Transcription of new } \\
\text { vocabulary }\end{array}$ & 0 & 0 & 0 & 0 & 116 & 0 & 116 & 6 \\
\hline $\begin{array}{l}\text { 5. Coverage of vocabulary into } \\
\text { suitable contexts or situations }\end{array}$ & 88 & 122 & 44 & 111 & 211 & 33 & 609 & 60 \\
\hline 6. Providing meaning of every word & 0 & 0 & 0 & 213 & 0 & 41 & 254 & 32 \\
\hline 7. Classification of a new words & 0 & 0 & 0 & 34 & 63 & 32 & 129 & 48 \\
\hline $\begin{array}{l}\text { 8. Level of Appropriateness of new } \\
\text { vocabulary }\end{array}$ & 122 & 166 & 159 & 231 & 172 & 50 & 900 & 100 \\
\hline Total & 363 & 436 & 383 & 1355 & 976 & 198 & 3521 & \\
\hline Percentage & $10.30 \%$ & $12.38 \%$ & 10.87 & 33.02 & 27.71 & 5.62 & $100 \%$ & \\
\hline
\end{tabular}

